\title{
Dispute avoidance procedure: Formulating a workable legal system in the Malaysian construction industry
}

\author{
Mohd Suhaimi Mohd Danuri ${ }^{*}$, Zahira Mohd Ishan $^{2}$, Nur Emma Mustaffa ${ }^{3}$, Saipol Bari. Abd-Karim ${ }^{4}$, \\ Othman Mohamed ${ }^{5}$, and Mahanim Hanid ${ }^{6}$, \\ 1,4,5,6 Department of Quantity Surveying, Faculty of Built Environment, University of Malaya, 50603, KL \\ ${ }^{2}$ Department of Management \& Marketing, Faculty of Economics \& Management, Universiti Putra \\ Malaysia \\ ${ }^{3}$ Department of Quantity Surveying, Faculty of Built Environment, Universiti Teknologi Malaysia, Skudai \\ *msuhaimi@um.edu.my
}

\begin{abstract}
Research on dispute avoidance procedure (DAP) particularly in Malaysia is lacking as most of the current research and development deals withvarious issues within the dispute resolution procedure and management field. It is therefore significant to conduct a country-specific research by exploring the viability of DAP based on socio-legal research. The aim of this article is two-fold: to present the perceptions of the Malaysian construction industry players on the substantive elements of a viable DAP mechanism and; to formulate a necessary legal reform to accommodate and support the formulated DAP mechanism within the Malaysian construction industry. As part of a socio-legal research approach, interviews were conducted with the selected construction industry players to disclosethe pattern, which may help to explain the underlying issues. NVivo software has been used to manage and organize the complete interview transcripts and facilitate the data analysis process for this study. Among others, this research suggests that a viable DAP mechanism consists of the following substantive elements, namely, to introduce the mechanism through contract and to provide a contractually binding settlement. In essence, this research also advocatesa necessary legal reform to accommodate and support the formulated DAP mechanism within the Malaysian construction industry. This research generally confirms that a countryspecific research is required through a socio-legal research.
\end{abstract}

Keywords: DAP, socio-legal research, construction industry, legal reform, legal system

\section{INTRODUCTION}

Dispute has been commonly described as inevitable in the construction industry. Therefore it is important to focus on identifying and managing conflicts at the soonest possible to avoid it from escalating into a dispute. In this regard, dispute avoidance procedure or process (DAP) has gained popularity in the construction industry of some major jurisdiction, although, it is entrenched mainly as trade practices and customs in a large infrastructure project through an agreement between the parties and incorporation of relevant clause in the standard forms of contract (Mohd Danuri et al., 2010; Mohd Danuri et al., 2015).

The term DAP has been frequently used by Gerber in her articles [see (Gerber, 1999, 2000, 2001; Gerber \& Ong, 2011a, 2011b)]. The fundamental difference between dispute resolution and dispute avoidance has also been discussed in the previous literature (Mohd Danuri et al., 2010; Mohd Danuri et al., 2015). The main characteristic of dispute resolution procedure is that it will only come into exist if there is a dispute and reference be made to it. Generally, the mechanisms under dispute resolution procedure can be categorized into three (3) main mechanisms namely, litigation, arbitration and alternative dispute resolution(ADR). Unlike dispute resolution procedure, DAP is a mechanism provided usually in the contract to effectively avoid disagreement from escalating into dispute, which means that the system is already in operation even before any dispute exists (Cheung \& Suen, 2002; Gerber, 1999), as shown in Figure 1.

DAP involves an independent third party intervention and the procedure must be established at the time the parties entered into a contract. The philosophy underlying the DAP concepts advocates the problem without delay during the construction process of which conflicts are dealt with and resolved before it escalates into a major disagreement (dispute) that could last for duration of contract or even after the project is completed (Thompson et al., 2000). This article adopts the works of Mohd Danuri et al. (2010) and Mohd Danuri et al. (2015) which categorizes the existing DAP into three, namely, dispute review board (DRB), dispute adjudication board (DAB) and combined dispute board (CDB) [refer Table 1]. 


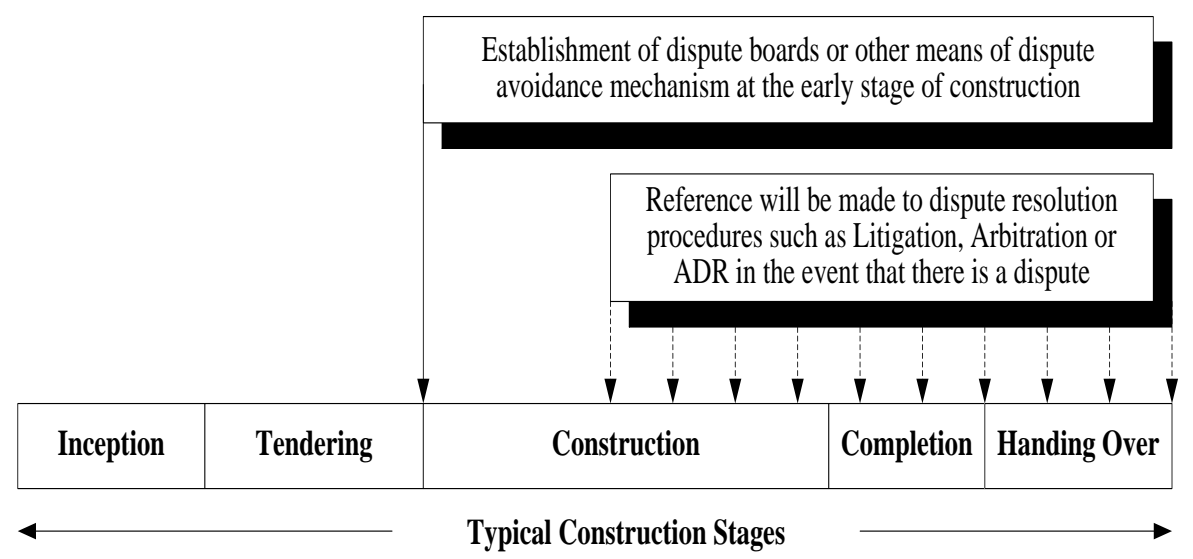

Figure 1: Interception of dispute

(Mohd Danuri et al., 2010, p. 353)

According to Friedman (1969), a workable legal system normally constitutes two major elements; structural and substantive. Structural elements are "the institutions or mechanisms themselves, the forms they take and the processes that they perform" (Friedman, 1969, p. 34) On the other hand, substantive elements are the laws such as "the rules, doctrines, statutes and....all other rules and decisions which govern, whatever their formal status" (Friedman, 1969, p. 34). For instance, Mohd Danuri et al. (2010) and Mohd Danuri et al. (2015) have identified and summarized the structural elements of the three existing DAP mechanisms, into form and process [refer Table 2].

Table 1: Proposed Categorisation

Adapted from Brewer (2007), Fenn et al. (1997) and Gerber (2001)

\begin{tabular}{|c|c|}
\hline \multicolumn{2}{|c|}{ Dispute Avoidance/Conflict Management } \\
\hline Management methods & $\begin{array}{l}\text { Non-escalation mechanisms } \\
\text { non-binding*/binding** }\end{array}$ \\
\hline $\begin{array}{l}\text { Quality matters } \\
\text { - Total quality management } \\
\text { - Co-ordinated project information } \\
\text { - Quality assurance } \\
\text { Choice of procurement systems } \\
\text { - Partnering } \\
\text { - Alliancing } \\
\text { Bespoke contracts }\end{array}$ & $\begin{array}{l}\text { - } \quad \text { Negotiation*/** } \\
\text { - } \quad \text { Project mediators* } \\
\text { - } \quad \text { Project arbitrators** } \\
\text { - } \quad \text { Dispute resolution adviser (DRA)*/** } \\
\text { Dispute avoidance procedure (DAP) } \\
\text { - } \quad \text { Dispute review board (DRB)* } \\
\text { - } \quad \text { Dispute adjudication board (DAB) })^{* *} \\
\text { - } \quad \text { Combined dispute board (CDB)*/** }\end{array}$ \\
\hline \multicolumn{2}{|c|}{ Dispute Resolution } \\
\hline non-binding & binding \\
\hline $\begin{array}{ll}\text { - } & \text { Conciliation } \\
\text { - } & \text { Mediation } \\
\text { - } & \text { Executive tribunal }\end{array}$ & $\begin{array}{ll}\text { - } & \text { Litigation } \\
\text { - } & \text { Arbitration } \\
\text { - } & \text { Adjudication } \\
\text { - } & \text { Expert determination }\end{array}$ \\
\hline
\end{tabular}


Table 2: The summary of form and process of the existing DAP mechanisms Adapted from AAA (2007); DRBF (2010); ICC (2008)

\begin{tabular}{|c|c|c|c|}
\hline $\begin{array}{l}\text { The Existing DAP } \\
\text { Mechanisms }\end{array}$ & Form & \multicolumn{2}{|c|}{ Process } \\
\hline $\begin{array}{c}\text { Dispute Review Board } \\
\text { (DRB) }\end{array}$ & \multirow{3}{*}{$\begin{array}{l}\text { Established at the commencement of the } \\
\text { project, preferably as part of the contract. The } \\
\text { dispute board panel normally consists of } \\
\text { three members but could differ subject to the } \\
\text { complexity and the nature of the project. } \\
\text { Alternatively can be established in } \\
\text { accordance with the provisions of the } \\
\text { Contract or, where the Contract is silent, in } \\
\text { accordance with the available Rules, Guide or } \\
\text { Procedures. The dispute board panel is } \\
\text { maintained and throughout its duration as } \\
\text { contractually agreed by the parties. }\end{array}$} & \multirow{3}{*}{$\begin{array}{l}\text { The dispute board panel } \\
\text { visits the job site } \\
\text { periodically with the } \\
\text { purpose of establishing } \\
\text { the working } \\
\text { relationships and } \\
\text { understanding of the } \\
\text { conditions that may give } \\
\text { rise to disputes. Subject } \\
\text { to the available Rules, } \\
\text { Guide or Procedures, } \\
\text { disputes arising out of } \\
\text { or in connection with the } \\
\text { contract shall or may be } \\
\text { submitted, in the first } \\
\text { instance, to the } \\
\text { dispute board panel. }\end{array}$} & $\begin{array}{l}\text { DRB issues } \\
\text { 'Recommendations' } \\
\text { with respect to any } \\
\text { dispute referred to it. }\end{array}$ \\
\hline $\begin{array}{c}\text { Dispute Adjudication } \\
\text { Board (DAB) }\end{array}$ & & & $\begin{array}{c}\text { DAB issues 'Decisions' } \\
\text { with respect to any } \\
\text { dispute referred to it. }\end{array}$ \\
\hline $\begin{array}{l}\text { Combined Dispute Board } \\
\text { (CDB) }\end{array}$ & & & $\begin{array}{l}\text { CDB normally issues } \\
\text { Recommendations with } \\
\text { respect to any dispute } \\
\text { referred to it but may } \\
\text { issue a Decision if a } \\
\text { party so requests and } \\
\text { no other party objects. }\end{array}$ \\
\hline
\end{tabular}

\section{RESEARCH METHODOLOGY}

This research employs Friedman's (1969) identification of the two major elements of a workable legal system, namely the structural and substantive elements, together with the influence of legal culture; in the quest to formulate a viable DAP mechanism for the Malaysian construction industry. The findings were derived from the analysis of a research in which some of its other findings have been published in Mohd Danuri et al. (2010) and recently in Mohd Danuri et al. (2015). In short, this research examines the perceptions of the industry players (Reisinger, 2009) by acknowledging the suggestions made by Samovar et al. (1981) that the similarity in the peoples' perceptions reveals the culture in how they understand a particular issue. Furthermore, there is a theoretical position which asserts that law is "a system or body of law tied to specific levels or kinds of culture" (Friedman, 1969, p. 37).

The qualitative research methodology employed by this research has been extensively reported in Mohd Danuri et al. (2010) and Mohd Danuri et al. (2015). In a nutshell, the data collected through interview of selected respondents were analysed to reveal patterns that help formulate a viable DAP mechanism. NVivo software has been used to manage and organise complete interview transcripts and facilitate data analysis process for this study. This research involved 29 interviewees consisting of clients, contractors, consultants, regulators of construction industry and lawyers specializing in construction law.

Research has found that the existing DAP mechanisms dictated in Table 2 are not presently viable for the Malaysian construction industry, mainly due to the issue of cost in maintaining the mechanism throughout the project implementation until completion (Mohd Danuri et al., 2015). In view of this, a modified version of DAP mechanism has been formulated to introduce a viable DAP mechanism. For instance, Mohd Danuri et al. (2015) has suggested the structural elements for a viable DAP mechanism, i.e. in the form of an 'involvement of top management' from both contracting parties and through the process of 'discussion and negotiation'. Figure 2 shows the structural elements for a viable DAP mechanism. 
This article presents and discusses the substantive elements perceived by the stakeholders and players in the Malaysian construction industry to complement the structural elements and to formulate a workable legal framework for the DAP system.

\section{Contractually Introducing DAP at the Early Stage}

The proposed DAP mechanism is beneficial to be established at the earlier stage of a project through contract rather than on an ad-hoc basis because the increase in management cost should be very minimal without the involvement of an outside third party. The interviewees believed that ideally, DAP should be introduced at the contract stage by providing a clause in the construction contract to enable a speedy and amicable resolution of construction dispute. For example, both parties shall contractually agree to appoint their top management personnel who can decide on both technical and financial matters of a project. Similarly, the sub-contracting parties shall also get their top management personnel who can make a decision and having financial authority to represent the sub-contractors. In turn, this shapes the parties mindset to always try to avoid any disagreement from escalating into a full blown dispute. The following sub-theme (s-t) explains why the interviewees perceive it so:

\section{s-t 1: Fastest and ideal way is through contract}

It is suggested that the fastest and ideal way to introduce the proposed DAP mechanism is by incorporating a clause setting out the same in the construction contract. The mechanism can be provided as an option or alternative to the currently available dispute resolution mechanism in the contract in order to help reduce dispute.

I think the best thing is to put in the contract....to encourage sentiments of consultation and to encourage them to avoid dispute or if there is any dispute, quickly resolved it through this procedure and as I said to further reduce the number of dispute. (Interviewee IR/01)

The faster way should be put into the contract, so we have the legal bind there. That is the fastest way...

(Interviewee PubCL/01)
Just like mediation. They put in the contract. Chances are, people will follow. Of course this will take some time.

Interviewee SR/02)

The following sub-theme (s-t 2) reveals that, unlike the existing DAP mechanisms which have the involvement of a third partywho will then decide or recommend the resolution of any disagreement, the settlement agreement reached through the proposed viable DAP regime which only involves both parties' top management personnel should be made contractually binding on both parties.

\section{$s-t$ 2: Contractually binding}

It is suggested that, for the proposed viable DAP regime which only involves both parties' top management personnel, the settlement agreement reached should be made contractually binding on both parties. This is in fact similar to the negotiated resolution or mutual agreement through a successful mediation. It must be noted that the interviewees have raised their concern regarding the enforceability issues of a mediation settlement agreement. This is supported by a statement from a prominent arbitrator, who observed that:

Not effective, there is no enforceability coming out of it, so they have problem with that.

(Interviewee ConstrLaw/01)

The above statement may be seen as biased because it comes from an arbitrator who will normally support arbitration at all time. However, a respondent who represents public client is also of the view that mediation is just providing assistance to both parties and it is all up to the parties to agree on a settlement to resolve the dispute.

The mediation concept is to advise only; it's just advice only, right! It's up to both parties whether to agree or not. (Interviewee PubCL/02)

Nevertheless, similar to an agreement reached through a successful mediation resulting in a signed written agreement, a DAP settlement agreement reached through discussion and negotiation is also legally binding as any other written contract. 


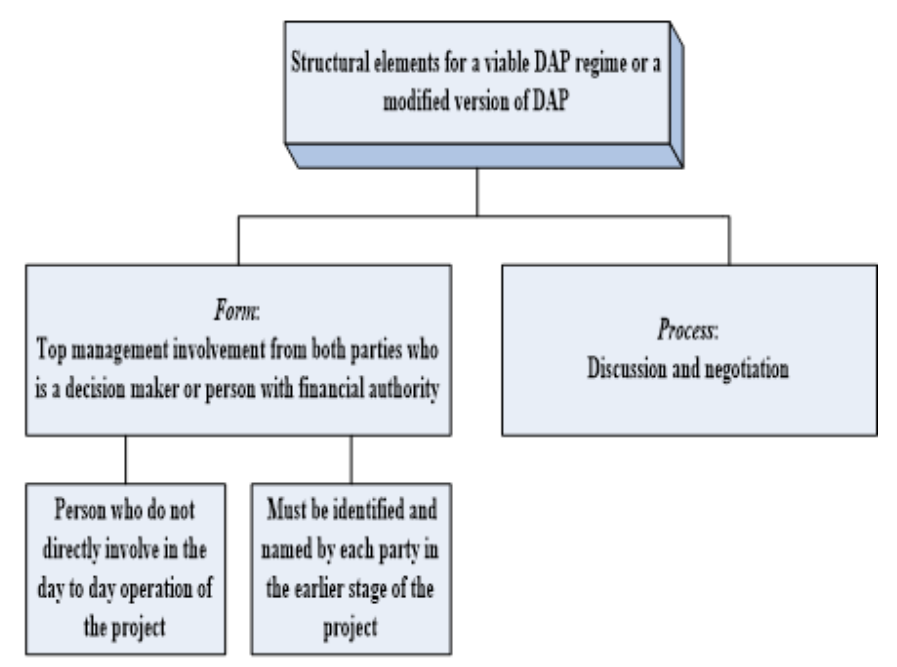

Figure 2: Structural elements for a viable DAP mechanism (Mohd Danuri et al., 2015).

For instance, section 10(1) of Malaysia Contracts Act 1950 recognizes an agreement as contract "...if they are made by the free consent of parties competent to contract, for a lawful consideration and with a lawful object, and are not hereby expressly declared to be void". However, although the parties are expected to resolve all disputes resulting in a contractually binding agreement, they may choose to agree on certain matters and disagree with other issues, especially if the latter involves a challenging legal issue. At least, the 'discussion and negotiation' at the top management level may help the parties to narrow down the issues in dispute.

Further, the following substantive element suggests that any statements made during the process of 'discussion and negotiation' with the purpose to compromise on certain issues in an attempt to settle a dispute, ideally should be made inadmissible in the subsequent proceedings.

\section{Inadmissible}

The admissibility issue is more readily accepted in the existing DAP mechanism as it involves decisions or recommendations made by an external third party that they normally called as dispute board (DB). For instance, the American Arbitration Association (AAA) dispute resolution board guide and the Dispute Resolution Board Foundation (DRBF) practices and procedures permit the determination of the board's or specifically the board's written report to be admissible in the subsequent arbitral or court proceedings (AAA, 2007; ICC, 2008). Similarly, subclause 20.6 of the 1999 FIDIC Red Book and Article 25 of ICC Dispute Board Rules also provide that the $\mathrm{DAB}$ or $\mathrm{DB}$ decision is admissible in the subsequent proceedings.
This is reinforced by the industry players' perception that the existing DAP's decision or recommendation should be made admissible. The argument for this is that admissibility may help by not wasting time having to start all over again in a later proceeding. They feel that the decision of DAP should be made admissible in the later proceedings by using it as a guide or stronger point to defend their case. This admissibility issue also shows their confidence on DAP, which has been voluntarily appointed and paid at the very early stage and expected to resolve disagreements related to the project justifiably as they arise. The following are the excerpts related to the admissibility issues in the existing DAP mechanisms:

To me, because you are appointing the DAB to resolve the dispute, I think whatever their decision it must be justified. There must be a reason for the decision. So that reason, if you admit in court it will assist the process. I do believe it should be admissible.

(Interviewee ConstrLaw/03)

You see, they give a recommendation you don't follow, so eventually when the dispute scalates to, the arbitrators will then and look at all these recommendation, why didn't you follow? If you had followed, would you be having this problem now that you are asking? Is it? Then that will be the logical question that they will ask. (Interviewee ConstrLaw/04) 
However, since the structural elements of a viable regime of DAP has been proposed in the form of an 'involvement of top management' from both contracting parties and, through the process of 'discussion and negotiation' (refer to Figure 2), it is expected that in the midst of discussion and negotiation it may involve both parties compromising on certain issues. It is anticipated that the settlement of dispute in the proposed viable DAP regime is in fact almost similar to mediation, but with an exception that in this DAP regime there is no involvement of a third party and the contractual parties resolve the dispute by themselves. Relevant to the issue of admissibility, the common law has recognized the statement 'without prejudice' which basically carries the meaning, without loss of any rights and applicable especially during a negotiation or settlement of dispute.

In this regard, Justice Walker in the case of Unilever v Proctor \& Gamble Co. 1999 EWCA Civ 3027; [2000] 1 WLR 2436 had examined the previous case laws and suggested that without prejudice privilege does not prevent the admission into evidence:

(1)...when the issue is whether without prejudice communications have resulted in a concluded compromise agreement, those communications are admissible....

(2) Evidence of the negotiations is also admissible to show that an agreement apparently concluded between the parties during the negotiations should be set aside on the ground of misrepresentation, fraud or undue influence....

(3) Even if there is no concluded compromise, a clear statement which is made by one party to negotiations, and on which the other party is intended to act and does in fact act, may be admissible as giving rise to an estoppel....

(4) Apart from any concluded contract or estoppel, one party may be allowed to give evidence of what the other said or wrote in without prejudice negotiations if the exclusion of the evidence would act as a cloak for perjury, blackmail or other unambiguous impropriety....the exception should be applied only in the clearest cases of abuse of a privileged occasion...

It illustrates that irrespective of whether or not the statement about 'without prejudice' is expressly made, the parties should be cautious that the court may take into consideration of what actually happening at mediation in order to determine whether the settlement agreement enforceable by the law. For example under Section 14 of the Malaysia Contracts Act 1950, the court may examine whether the settlement agreement is free from coercion, undue influence, fraud, misrepresentation or mistake. Nevertheless, the evidence of the content of a compromise settlement agreement itself generally shall not be made admissible at trial. Lord Griffiths in Rush \& Tompkins Ltd v Greater London Council [1989] AC 1280 at 1299-1300 said that:

The (without prejudice) rule applies to exclude all negotiations genuinely aimed at settlement whether oral or in writing from being given in evidence. A competent solicitor will always head any negotiating correspondence "without prejudice" to make clear beyond doubt that in the event of the negotiations being unsuccessful they are not to be referred to at the subsequent trial. However, the application of the rule is not dependent upon the use of the phrase "without prejudice" and if it is clear from the surrounding circumstances that the parties were seeking to compromise the action, evidence of the content of those negotiations will, as a general rule, not be admissible at the trial and cannot be used to establish an admission or partial admission.

Thus, for certainty reason the proposed viable DAP regime should clearly state that if the parties mutually agree, any views expressed, suggestions made or admitted by the parties in the course of negotiating a settlement should be made inadmissible. However, this article suggests that the DAP settlement agreement itself once concluded should be made admissible to the extent to enable it to be enforced through the court of law. For instance, Article 14 (Part One) the UNCITRAL Model Law on International Commercial Conciliation, 2002 tries to deal with the enforcement of settlement agreements in the following words:

If the parties conclude an agreement settling a dispute, that settlement agreement is binding and enforceable... [the enacting State may insert a description of the method of enforcing settlement agreements or refer to provisions governing such enforcement].

Further, Section 15(2)(d) of the Malaysia Mediation Act 2012 provides that mediation communication may be disclosed in order to implement or enforce a settlement agreement. In other words, a mediation settlement agreement should be admissible only for the purposes of implementation or enforcement of a settlement 
agreement. However, section 16(1) of the Mediation Act 2012 reads that any views expressed, suggestions made by the other party in respect of a possible settlement of the dispute or admitted in the course ofnegotiating a settlement should not be made admissible as evidence in the subsequent proceedings. In addition, subject to limited circumstances specified by section 16(2)(a)-(f) of the Mediation Act 2012, the court may take into consideration of what actually happening at mediation to the extent of examining whether the settlement agreement is enforceable by the law.

It is also suggested that a DAP settlement agreement like an ordinary mediation settlement is in fact enforceable just like any other settlement agreement or contract, subject to the common law principle and in particular in accordance with the Malaysia Contracts Act 1950. The issue of admissibility should be properly dealt since it is highly related to the enforceability issue. For instance, in this study, it is found that unenforceability is considered as one of the reasons that discourage the industry players from using mediation. This is supported by a statement from a prominent arbitrator, who observed that:

Not effective, there is no enforceability coming out of it, so they have problem with that.

(Interviewee ConstrLaw/01)

Thus, a legal reform may help to effectively enforce a DAP settlement agreement by amending the existing relevant Act of Parliament to tackle the admissibility issues and incorporate the enforcement procedure for a DAP settlement agreement achieved through discussion and negotiation between both contracting parties.

Next, the following substantive element suggests that whether or not to impose limitation of power would depend on the composition or knowledge of both parties' top management personnel.

\section{Limitation of power}

Basically, the interviewees agree that the issue of limitation should be left open within the terms of reference prior to the establishment of the mechanism. The following extracts describe the responses.

The bigger point or more crucial point is there should be some limitation. What those limitations are is left to the parties to agree on. (Interviewee PriCL/01)
That should not be [limitation]. Because you appointed the board or the person, because of his knowledge....both parties have agreed. That should not be an issue.

(Interviewee IR/01)

The parties' decision whether or not to impose limitation of power on DAP would depend on the composition or knowledge of the members. This is to protect the parties especially if the DAP members are not fully equipped or well versed to handle legal issues which may endanger the parties if an incorrect decision is made. Such a limitation of power to resolve dispute should be applied for the proposed viable DAP regime which solely involves both parties' top management personnel unless the personnel have the appropriate knowledge, both technically and legally, and ideally they should have been agreed upon by both parties.

Based on the theoretical position that a legal system is tied to specific kinds of culture which subsequently determines the structural and substantive elements of a workable legal system (Friedman, 1969), the following Table 3 summarizes the formulation of a viable DAP regime for the Malaysian construction industry.

\section{RECOMMENDATION}

The most crucial legal aspect which has been identified in this study is the recognition and enforcement of the DAP settlement agreement reached through discussion and negotiation between both contracting parties without the involvement of any third party, henceforth referred to as a nonmediated settlement agreement. This article recommends that the amendments to the relevant statute should be made by incorporating the enforcement procedure for a non-mediated settlement agreement. In order to do this, it is suggested that the most suitable statute to be amended in Malaysia is the Construction Industry Payment and Adjudication Act 2012 (CIPAA). It is anticipated that other local statutes such as the Arbitration Act 2005 and Mediation Act 2012 are not suitable since both Acts specifically dealt with arbitration and mediation.

For instance, the preamble section of Arbitration Act 2005 read as follows:

An Act to reform the law relating to domestic arbitration, provide for international arbitration, the recognition and enforcement of awards and for related matters. 
Table 3: Formulation of a viable DAP regime

\begin{tabular}{|c|c|c|}
\hline \multicolumn{2}{|c|}{ STRUCTURAL ELEMENTS } & \multirow{2}{*}{ SUBSTANTIVE ELEMENTS } \\
\hline Form & Process & \\
\hline \multirow{4}{*}{$\begin{array}{l}\text { In the form of involvement } \\
\text { of top management from } \\
\text { both parties who is a } \\
\text { decision maker or person } \\
\text { with financial authority } \\
\text { - Person who do not } \\
\text { directly involve in the } \\
\text { day to day operation } \\
\text { of the project } \\
\text { - Must be identified and } \\
\text { named by each party } \\
\text { in the earlier stage of } \\
\text { the project }\end{array}$} & \multirow{4}{*}{$\begin{array}{l}\text { Through the process of } \\
\text { discussion and negotiation }\end{array}$} & To be provided through contractual mechanism. \\
\hline & & Settlement agreement is contractually binding the parties. \\
\hline & & $\begin{array}{l}\text { Any views expressed, suggestions made or admitted by the } \\
\text { parties in the course of negotiating a settlement, should be } \\
\text { made inadmissible, but the DAP settlement agreement itself } \\
\text { once concluded should be made admissible to the extent to } \\
\text { enable it to be enforced through the court of law. }\end{array}$ \\
\hline & & $\begin{array}{l}\text { Limitation of power to resolve dispute should be applied for } \\
\text { the proposed viable DAP legal regime which solely involves } \\
\text { both parties' top management personnel, unless both } \\
\text { personnel have the appropriate knowledge, technically and } \\
\text { legally, and ideally should have been agreed upon by both } \\
\text { parties. }\end{array}$ \\
\hline
\end{tabular}

The preamble section of the CIPAA provides a room for amendment to be made by allowing the parties in disputes to consider negotiation prior to adjudication, as a means of achieving settlement of disputes without the involvement of a neutral third party such as arbitrator, mediator or adjudicator. In addition, unlike the other two statutes, CIPAA is a statute designed specifically for the construction industry and inevitably makes it suitable to be amended.

In this regard, section 25 and sub-section 12(2) of CIPAA provide that the Act is introduced to facilitate regular and timely payment through the adjudication process where the adjudicator shall make a decision within certain time limit as empowered by the Act. However, unlike adjudication, it is recommended that the parties may choose to resolve any conflict or disagreement by concluding a settlement agreement achieved through their own discussion and negotiation, without the involvement of a third party prior to adjudication or before the matters finally decided by adjudicator under the CIPAA. Hence, in order to enforce a non-mediated settlement agreement, it is suggested to add the following sentence after the fourth line of the Preamble section:

This Act shall also provide for the recognition and enforcement of a nonmediated settlement agreement to settle any disagreements or conflicts arising out from the contract which may be achieved by the parties prior to adjudication.
It is suggested that CIPAA should be amended to allow a non-mediated settlement agreement to be enforced through a similar mechanism as provided in sections 13 and 14 of the Mediation Act 2012. This suggestion could be achieved by including a new Part in the CIPAA to be known as Part IVA which could be added immediately after the existing Part IV. Under the new Part IVA which may be entitled as, Part IVA: Enforcement of a non-mediated settlement agreement, the following sentences could be provided:

31A. Non-mediated settlement agreement (1) Any person may choose to resolve any conflict or disagreement by concluding a non-mediated settlement agreement achieved prior to adjudication or before the matters finally decided by adjudicator under this Act.

(2) A non-mediated settlement agreement shall only be negotiated and resolved among the conflicting parties himself, or if he is a company, through his officer empowered with such function, or by his agent.

(3) A non-mediated settlement agreement shall be binding on the parties.

(4) If proceedings have been commenced in court, the non-mediated settlement agreement may be recorded before the court as a consent judgment or judgment of the court.

31B. Non-mediated settlement agreement to be in writing

(1) A non-mediated settlement agreement 
shall be in writing.

(2) A non-mediated settlement agreement shall be in the national language or English language.

(3) A non-mediated settlement agreement that does not comply with subsections (1) and (2) shall be void.

31C. Non-mediated settlement agreement to be signed, etc.

(1) A non-mediated settlement agreement shall be signed by or on behalf of all parties to the agreement.

(2) No person, officer or agent shall sign a non-mediated settlement agreement unless such non-mediated settlement agreement has been duly completed.

(3) A non-mediated settlement agreement that does not comply with subsections (1) and (2) shall be void.

As mentioned earlier, section $31 \mathrm{~A}$ is similar to sections 13 and 14 of the Mediation Act 2012. Additionally, sections $31 \mathrm{~B}$ and $31 \mathrm{C}$ are provided to safeguard the issue of certainty and clarity of the settlement agreement by requiring it to be in writing and signed. This is significant because the parties may agree to conclude a non-mediated settlement agreement between them without the involvement of a neutral third party.

\section{CONCLUSION}

In essence, this article explores the possible substantive elements that suit the structural elements of a viable DAP mechanism in the Malaysian construction industry through a socio-legal research. A viable DAP mechanism has been formulated by employing the theoretical position that a legal system is tied to specific kinds of culture which subsequently determine the structural and substantive elements of a workable legal system. This article also suggests a necessary legal reform to accommodate and support the formulated DAP mechanism within the Malaysian construction industry. It is hoped that if due consideration is given to this suggestion, it would attract the industry to genuinely discuss and negotiate settlement as an initial step in attempting to avoid conflict and resolve dispute without resorting to ADR or litigation.

\section{REFERENCES}

AAA. (2007). AAA Dispute Resolution Board Guide Specifications. Retrieved 5 April, 2011, http://www.adr.org/sp.asp?id=22028 - AG

Abowitz, D. A., \& Toole, T. M. (2010). Mixed

Method Research: Fundamental Issues of Design, Validity, and Reliability in Construction Research.Journal of Construction Engineering and Management, 136(1), 108-116.

Boyatzis, R. E. (1998). Transforming qualitative information: Thematic analysis and code development: Thousand Oaks: Sage Publications.

Brewer, G. (2007). Dispute Avoidance. Contract Journal, 437(6611), 22.

Chan, E. H. W., \& Tse, R. Y. C. (2003).Cultural Considerations in International Construction Contracts. Journal of Construction Engineering and Management, 129(4), 375381.

Cheung, S.-O., \& Suen, H. C. H. (2002). Amultiattribute utility model for dispute resolution strategy selection. Construction Management and Economics, 20(7), 557568.

D'Amato, A. A. (1984).Jurisprudence: A descriptive and normative analysis of law. The Netherlands: Martinus Nijhoff Publishers.

DRBF. (2010). DRBF Practices and Procedures. The Report. Retrieved 5 March, 2011, from http://www.drb.org/manual/2.8_final_1206.pdf

Easterby-Smith, M., Thorpe, R., \& Lowe, A. (1991). Management Research: An Introduction. London: Sage.

Fenn, P., Lowe, D., \& Speck, C. (1997). Conflict and dispute in construction. Construction Management and Economics, 15(6), 513518.

Friedman, L. M. (1969). Legal Culture and Social Development. Law \& Society Review, 4(1), 29-44.

Friedman, L. M. (1975). The legal system: a social science perspective. New York: Russell Sage Foundation.

Gerber, P. (1999). Construction Dispute Review Boards.Australasian Dispute Resolution Journal, 9-17.

Gerber, P. (2000).The changing face of construction dispute resolution in the international arena: where to from here?Australian Construction Law Newsletter (73), 5-9.

Gerber, P. (2001). Dispute avoidance procedures ("DAPs") - The changing face of construction dispute management. International Construction Law Review, 18(1), 122-129.

Gerber, P., \& Ong, B. (2011a). 21 Today! Dispute 
review boards in Australia: Past, present, future.Australasian Dispute Resolution Journal, 22(3), 180-191.

Gerber, P., \& Ong, B. (2011b).DAPs: When will Australia Jump on Board? Building and Construction Law Journal, 27(1), 4-29.

Guba, E. G. (1978).Towards a methodology of naturalistic inquiry in educational evaluation (CSE Monograph Series in Evaluation No.8).Los Angeles: Center for the Study of Evaluation.

Harmon, K. M. J. (2003). Effectiveness of Dispute Review Boards. Journal of Construction Engineering and Management, 129(6), 674.

Harmon, K. M. J. (2004). Construction Conflicts and Dispute Review Boards: Attitudes and Opinions of Construction Industry Members. Dispute Resolution Journal, 58(4), 66-75.

Hertogh, M. (2004).A 'European' Conception of Legal Consciousness: Rediscovering Eugen Ehrlich. Journal of Law and Society, 31(4), 457-481. doi: 10.1111/j.14676478.2004.00299.x

Hinchey, J. W., \& Perry, J. H. (2008).Perspective from the United States: Tensions between "Getting It Done" and "Getting It Right". Journal of Professional Issues in Engineering Education and Practice, 134(2), 231-239.

ICC. (2008). ICC Dispute Board Rules. Retrieved 15January, 2008, from http://www.iccwbo.org/uploadedFiles/Court/ DRS/dispute_boards/db_rules_2004.pdf

Merriam, S. B. (1998). Qualitative research and case study applications in education. San Francisco: Josey-Bass Publishers.

Miles, M. B., \& Huberman, A. M. (1994).

Qualitative data analysis:An expanded sourcebook(2nd ed.). Thousand Oaks: Sage Publications.

Mohd Danuri, M. S., Mohd Ishan, Z., Mustaffa, N. E., \& Jaafar, M. S. (2012). A revisit on thecurrent practice of dispute resolutionand ADR in theMalaysian construction industry. Journal of Design and BuiltEnvironment, 10, 1-13.

Mohd Danuri, M. S., Shaik Mohd Hussain, S. M. N. A., Mustaffa, N. E., \& Jaafar, M. S. (2010). Growth of Dispute Avoidance Procedure in the Construction Industry: a Revisit and New Perspectives. Const. L.J., 26(5), 347361 .
Mohd Danuri, M.S., Mohd Ishan, Z., Mustaffa, N.E.,Abd-Karim, S.B., Mohamed, O. \& ARahmin, R.A. (2015). Dispute Avoidance Procedure: Observing the Influence of Legal Culture towards a Workable Legal System. PertanikaJournal of Social Sciences and Humanities, 23(2), 509 - 535.

Patton, M. Q. (1987). How to Use Qualitative Methods in Evaluation. Newbury Park, CA: Sage Publications Inc.

Reisinger, Y. (2009). International Tourism: Cultures and Behavior. USA: Elsevier ButterworthHeinemann.

Samovar, L. A., Portar, R. E., \& Jain, N. C. (1981). Understanding Intercultural Communication. USA: Wadsworth Pub. Co.

Sarantakos, S. (2005). $\quad$ Social Research (3rd ed.). Basingstoke: Palgrave Macmillan.

Sarat, A. (1977). Studying American Legal Culture: An Assessment of Survey Evidence.Law \& Society Review, 11(3), 427-488.

Thompson, R. M., Vorster, M. C., \& Groton, J. P. (2000). Innovations to Manage Disputes: DRB and NEC. Journal of Management in Engineering, 16(5), 51-59.

Tso, J. (1999). Do You Dig Up Dinosaur Bones? Anthropology, Business, and Design. Design Management Journal, 10(4), 69-74.

Zulhabri, I., Jamalunlaili, A., \& Rosli, M. Z. (2008). Findings of Alternative Dispute Resolution(ADR) Application and ObstaclesTowards Active Development of ADR in the Malaysian Construction Industry. Paper presented at the 3rd Conference of Law and Technology 2008, Palm Garden Hotel Putrajaya. 